\title{
The Prevalence of Protrusion of Infraorbital Nerve into Maxillary Sinus identified on CT Scan of the Paranasal Sinuses at a Tertiary Hospital in Nepal
}

\author{
Gautam R', Adhikari D', Dhital M'1,Thakur S', Adhikari B² \\ ${ }^{1}$ Chitwan Medical College, Bharatpur, Nepal \\ ${ }^{2}$ Nepal Medical College, Kathmandu, Nepal
}

Received: March 20, 2018

Accepted: April 30, 2018

Published: June 30, 2018

Cite this paper:

Gautam R, Adhikari D, Dhital M, Thakur S, Adhikari B. The Prevalence of Protrusion of Infraorbital Nerve into Maxillary Sinus identified on CT Scan of the Paranasal Sinuses at a Tertiary Hospital in Nepal. Nepalese Journal of Radiology 2018;8(11):7-12.http://dx.doi.org/10.3126/njr.v8i1.20440

\begin{abstract}
Introduction: The variation in the course of infraorbital canal and protrusion of the infraorbital nerve through it to the maxillary sinus may lead to its accidental injury during reconstructive or endoscopic sinus surgery. Preoperative identification of this variant will prevent unintended injuries.
\end{abstract}

Methods: A retrospective study of 307 patients who underwent CT scan study of the paranasal sinuses at Chitwan Medical College, Nepal was conducted. The protrusion of infraorbital nerve to the maxillary sinus was identified and the length of the bony septum along with the infraorbital nerve was measured. It was further classified as Class I to III according to the length of the septum.

Results: The prevalence of protrusion of inferior orbital nerve in our study was $11.40 \%$ and bilateral protrusion was $5.8 \%$. The median length of the protruding component along with the septum was $4.9 \mathrm{~mm}$.

Conclusion: Preoperative identification of the normal protrusion of infraorbital nerve to the maxillary sinus will prevent accidental injuries during sinus surgery. CT scan of the paranasal sinus would be the modality of choice for identification of this variant.

Key words: Computed Tomography; Infraorbital Canal; Infraorbital Nerve

\section{INTRODUCTION}

Plain $\mathrm{x}$-ray as an imaging modality for evaluation of the paranasal sinuses has been almost completely replaced with computed tomography. CT scan is the diagnostic modality of choice for evaluation of the

Correspondence to: Dr. Rupesh Gautam Department of Radiology and Imaging Chitwan Medical College

Bharatpur, Nepal

Email: rupesh_gautam@hotmail.com paranasal sinuses following accidents and for pre-operative evaluation of sinus inflammatory 
disease or any tumoral lesion of the paranasal sinuses ${ }^{1}$. CT scan not only provides adequate information regarding the disease process but also identifies normal variants in relation to the paranasal sinuses. ${ }^{2}$ Identification of these normal variants is utmost important to reduce accidental surgical injuries.

The infraorbital nerve is terminal branch of maxillary nerve which in turn is the second branch (V2) of the trigeminal nerve. It leaves the pterygopalatine fossa to enter the orbit through the inferior orbital fissure. The nerve courses along the floor of the orbit through the infraorbital canal and exits normally from the infraorbital foramen of the maxillary bone along with the inferior orbital vein and artery. ${ }^{3,4}$ Variation in the course may result in protrusion of infraorbital nerve form the infraorbital foramen to the maxillary sinus. ${ }^{5,6}$ This protrusion of the infraorbital nerve renders it prone to accidental injury during maxillary sinus surgery. There are no published studies till date to identify the prevalence of this anatomical variation among Nepali population. This study aims to identify the prevalence of this normal anatomical variation.

\section{METHODS}

Three hundred CT scan of the paranasal sinuses were retrospectively selected and images were reviewed by two consultant radiologists with five years of experience in reporting CT scan images. All the CT scan was performed in a 16 slice multidetector CT scan machine (GE bright speed) at the Department of Radiology of Chitwan Medical College, Nepal from January 2017 to July 2017. The axial images were acquired at $3 \mathrm{~mm}$ with reconstruction at $0.625 \mathrm{~mm}$ thickness. Images were acquired with bone and soft tissue algorithm. Coronal and sagittal reformation was done. The patients with trauma involving the orbital floor were excluded from the study. The presence or absence of protrusion of infraorbital nerve to the maxillary sinus was noted. Protrusion was confirmed with entire circumference of the infraorbital canal along with the infraorbital nerve was noted within the maxillary sinus without touching the walls. ${ }^{1}$ The length of the protruding component along with the bony septum was measured on axial images. The variation whether bilateral or unilateral was also noted.

\section{RESULTS}

Total $307 \mathrm{CT}$ scan of the paranasal sinuses were reviewed for the study and out of which 201 were males and 106 were females. The median age of the patient was years 50 (range, 10 to 90 years). The prevalence of protrusion of infraorbital nerve to the maxillary sinus was noted in 35 patients with prevalence of $11.4 \%$. Bilateral protrusion was noted in 18 patients with prevalence of $5.6 \%$. The length of the protruding component was noted ranging from $0.9 \mathrm{~mm}$ to $8.9 \mathrm{~mm}$ with median length of $4.9 \mathrm{~mm}$. Class I protrusion (1-3 mm) was noted in 15 patients (42\%), Class II (4-6 $\mathrm{mm})$ in 17 patients $(48 \%)$ and class III (7-11 $\mathrm{mm})$ in 3 patients $(8.5 \%)$. The representative images are demonstrated at Figure No. 1, 2, 3 and 4. Similarly the tabulated data are described at Table No. 1 and 2.

\section{DISCUSSION}

Three hundred 307 CT scans of the paranasal sinuses were reviewed. The prevalence of protrusion of infraorbital nerve to the maxillary sinus was found to be $11.4 \%$. The protrusion was defined when entire circumference of the inferior orbital nerve was noted within the maxillary sinus without touching the walls. ${ }^{1}$ The protrusion was always accompanied with a bony septum. The length of the protruding component along with the bony septum was noted. They were classified as class I (1-3 $\mathrm{mm})$, II (4-6 $\mathrm{mm})$ and III (7-11 $\mathrm{mm}$ ) according to their length. Different classification system has been proposed for this variant. ${ }^{1,4,7}$ The definition and classification system for our study was adopted from the paper published by Lantos et al. ${ }^{1}$ Acgar et al in their study 


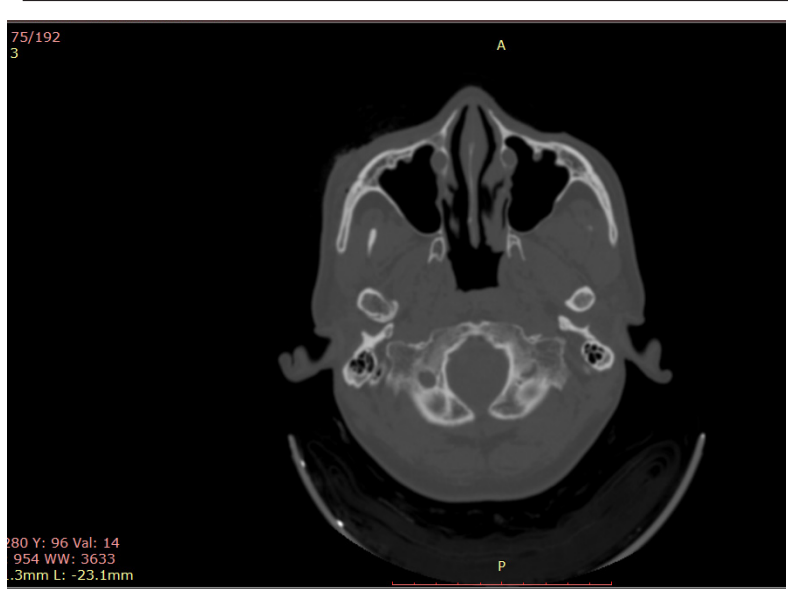

1. (a)

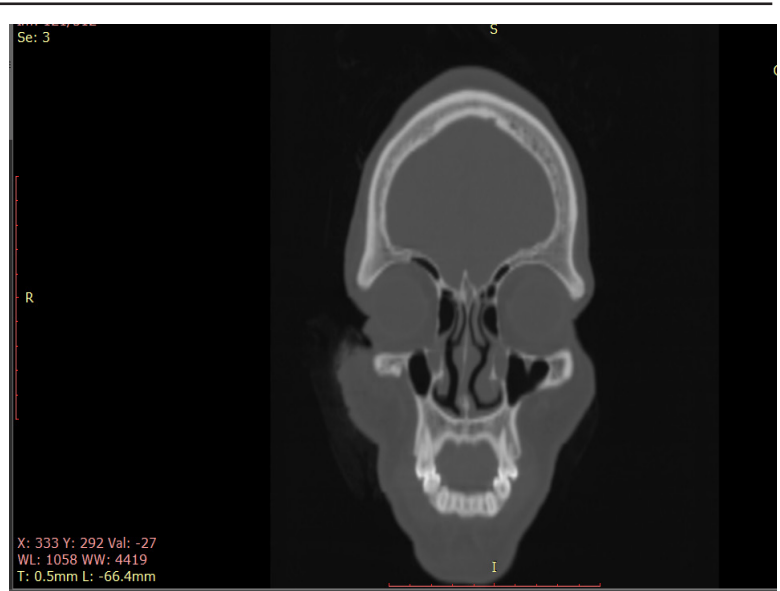

1. (b)

Fig 1 (a) and (b):Axial and coronal CT scan images of the paranasal sinuses demonstrating Type I protrusion (white arrow) of the left infraorbital nerve at the left maxillary sinus. The protrusion measured $3 \mathrm{~mm}$.
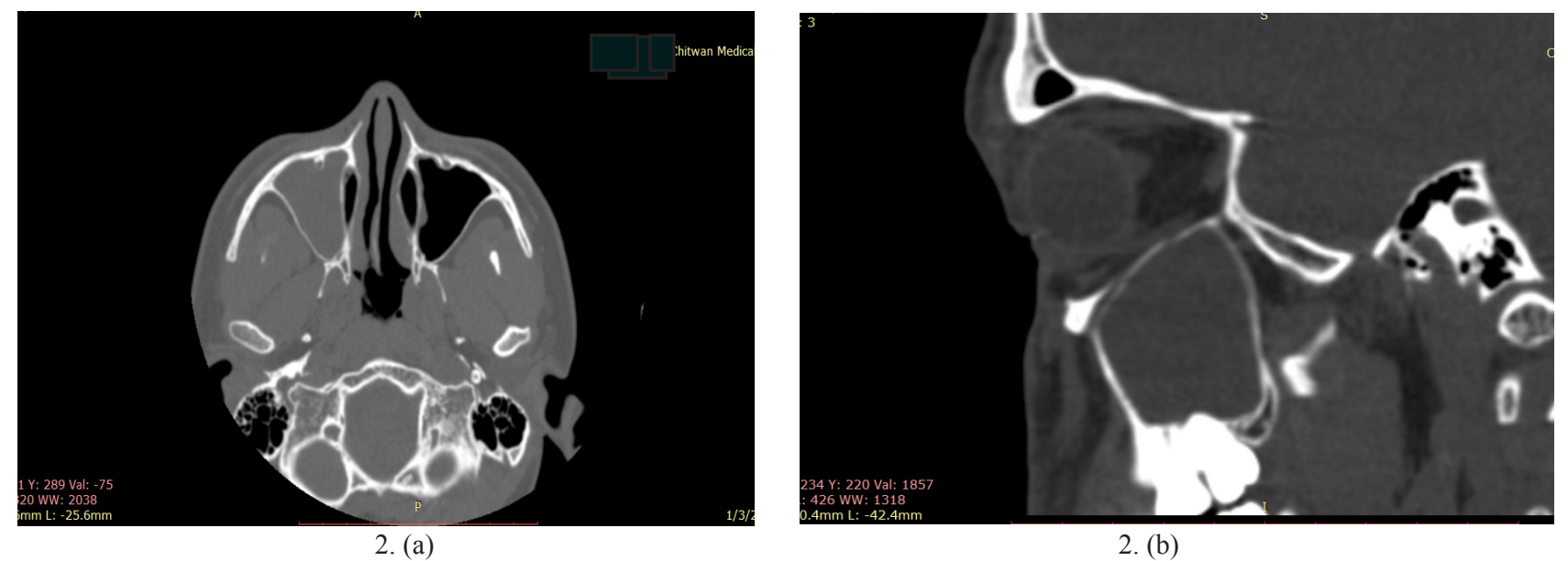

Fig $2 \boldsymbol{a}$ and $\boldsymbol{b}$ : Axial and sagittal CT scan images of the paranasal sinuses demonstrating Type I protrusion (white arrow in fig a and $b$ ) of the right infraorbital nerve at the right maxillary sinus. The protrusion measured $2.6 \mathrm{~mm}$.

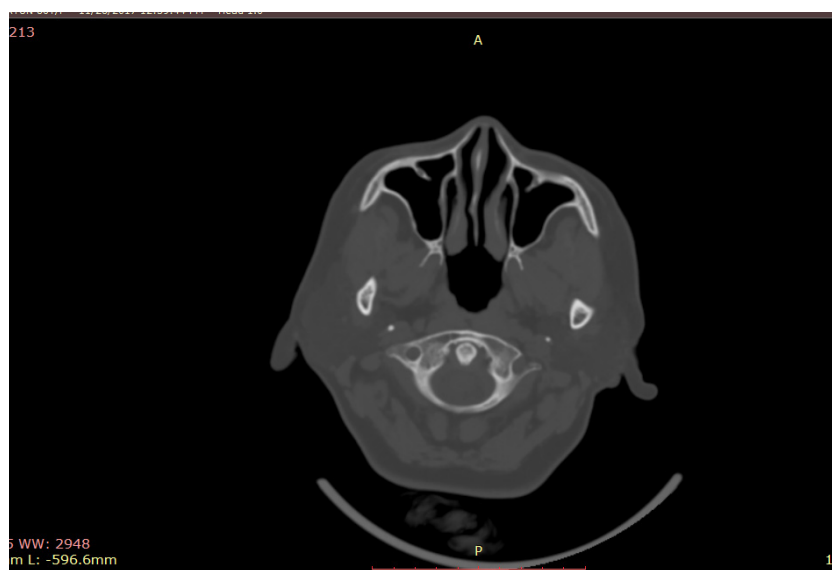

3. (a)

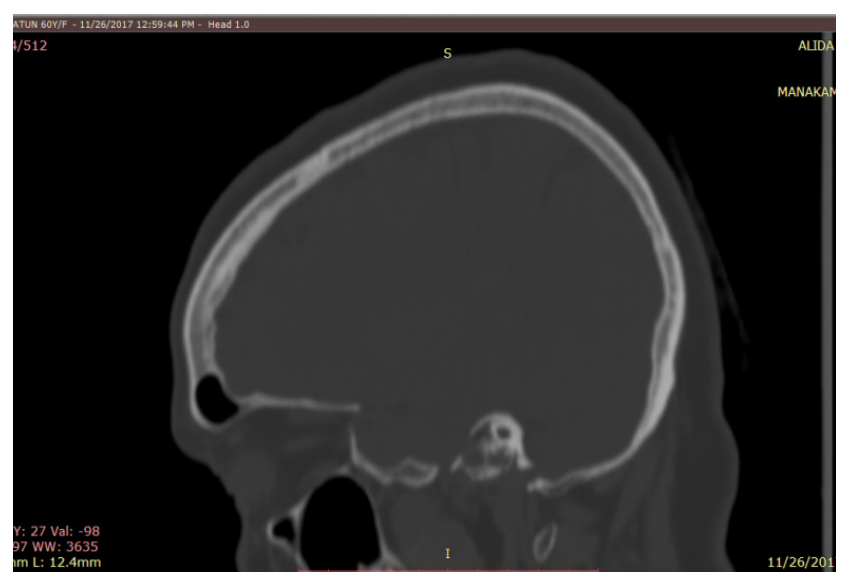

3. (b)

Fig 3a:Axial CT scan images of the paranasal sinuses demonstrating Type III protrusion of bilateral infraorbital nerve (white arrow) at the maxillary sinuses. The protrusion measured 8 mm. Fig 3b: Protrusion demonstrated on right sagittal image (white arrow). 


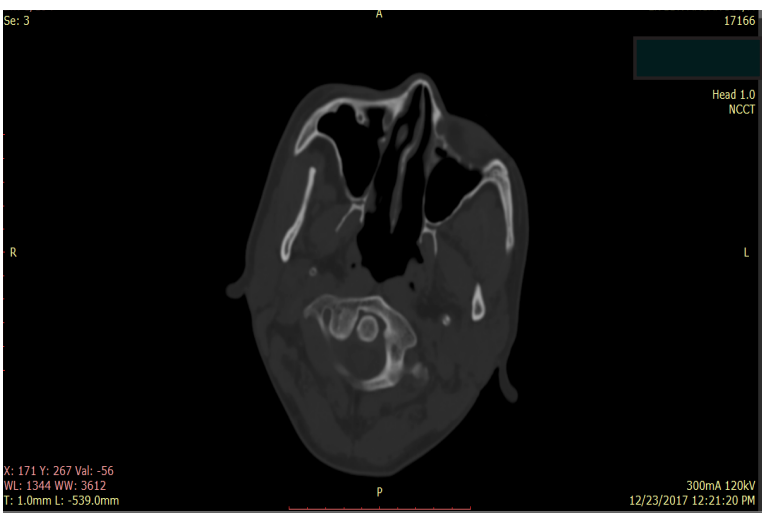

Fig 4: Axial CT scan images of the paranasal sinuses demonstrating Type II protrusion of the right infraorbital nerve ( white arrow) at the right maxillary sinus. The protrusion measured $4 \mathrm{~mm}$.

classified this variant into four subtypes as Type 1: within the maxillary bony roof, Type 2: partially protruding into maxillary sinus, Type 3: within the maxillary sinus, Type 4: located anatomically at the outer limit of the zygomatic recess of the maxillary bone. ${ }^{4}$ The definition by Lantos et al has specific measurements for classification and easy to follow.

Numerous variants of the paranasal sinuses are identified on $\mathrm{CT}$ scan of the paranasal sinuses. Earwaker in his study classified them into two categories as variant related to bone abnormality and other as sinus air cells extension. ${ }^{2}$ The commoner variants were related to nasal septum and middle turbinate. Similar results were noted by Karki et al on the study to identify the variants of paranasal sinuses among Nepali population. ${ }^{8}$ On reviewing the literature there are only few studies published related to identifying the protrusion of inferior orbital nerve to maxillary sinus and no published study as such was found from Nepal. This study is primarily aimed to find the prevalence of it among Nepali population.

The inferior orbital nerve lies within the inferior orbital canal, a thin rim of bone coursing along the orbital floor. The main nerve to the maxillary sinus is from the maxillary nerve via infraorbital and anterior, middle, and posterior superior alveolar nerves. ${ }^{9,} 10$ Orbital blow out fracture is the commonest orbital fracture and involves the orbital floor. ${ }^{11}$ There is high likelihood of fracture involving the inferior orbital canal and resultant injury to the inferior orbital nerve. This results in paresthesia of the face and lips. The protrusion of inferior orbital nerve to the maxillary sinus is a variant in the course of nerve. Similar to the prior studies on the literature this protrusion was invariably associated with a septum in our study. This variation in the course makes the nerve vulnerable to iatrogenic injury during surgeries of the paranasal sinuses or surgery of the maxillo-facial skeleton. The surgeries with high probability of iatrogenic injuries if not identified preoperatively are functional endoscopic sinus surgery (FESS) for maxillary sinus inflammatory disease, orbital reconstructive surgery and Caldwell-Luc operation among many others. ${ }^{12}$ Preoperative identification of this variant provides a good road map for the surgeons to prevent accidental injuries. ${ }^{13}$

The prevalence of this variant was found to be $11.6 \%$ and the median length of the protrusion with accompanying septum was $4.9 \mathrm{~mm}$ in our study where as in the study by Lantos et al it was noted to be present in $10.8 \%$ and the average length of the septum was $4 \mathrm{~mm}$.

Table 1: Characteristics of patients

\begin{tabular}{|l|l|l|l|} 
Total number of patients & Protrusion present & Unilateral protrusion & Bilateral protrusion \\
\hline 307 & $35(11.6 \%)$ & $17(5.5 \%)$ & $18(5.6 \%)$ \\
201 males: $65 \%$ & & & \\
106 females: $35 \%$ & & & \\
& & & \\
\hline
\end{tabular}


Table 2: Classification of the septum according to the length

\begin{tabular}{|l|l|}
\hline Type & No. of patients \\
\hline $1(1-3 \mathrm{~mm})$ & $15(42 \%)$ \\
\hline $2(4-6 \mathrm{~mm})$ & $17(48 \%)$ \\
\hline $2(7-11 \mathrm{~mm})$ & $3(8.5 \%)$ \\
\hline
\end{tabular}

\section{CONCLUSION}

On reviewing the literature no study as such from Nepal was found identifying the prevalence of protrusion of infraorbital nerve to the maxillary sinus among Nepali population. The identification of this variant and length of the protrusion should be mentioned in the radiology report for prevention of accidental iatrogenic injury to the infraorbital nerve.

\section{CONFLICT OF INTEREST}

None

\section{SOURCES OF FUNDING}

None

\section{REFERENCES}

1. Lantos JE, Pearlman AN, Gupta A et al. Protrusion of the infraorbital nerve into the maxillary sinus on CT: Prevalence, proposed grading method, and suggested clinical implications. AJNR Am J Neuroradiol 2016;37(2):349-353. http://dx.doi.org/10.3174/ajnr.A4588

2. EarwakerJ.Anatomic Variants in Sinonasal CT. Radiographics 1993;13(2):381- 415. https://doi.org/10.1148/ radiographics.13.2.8460226

3. Nguyen DC, Farber SJ, Um GT et al. Anatomical Study of the Intraosseous Pathway of the Infraorbital Nerve. $J$ Cranio fac Surg 2016;27(4):1094-1097. ht tps://doi.org/10.1097/ $\underline{\text { SCS.0000000000002619 }}$
4. Acar G, Ozen KE, Guler I, Buyukmumcu M.Computed tomography evaluation of the morphometry and variations of the infraorbital canal relating to endoscopic surgery. Braz J Otorhinolaryngol 2017;580:589. https://doi.org/10.1016/j. bjorl.2017.08.009

5. Kazkayasi M, Ergin A, Ersoy M, Bengi O,Tekdemir I, Elhan A. Certain Anatomical Relations and the Precise Morphometry of the Infraorbital Foramen-Canal and Groove:An Anatomical and Cephalometric Study. Laryngoscope 2001;111(4):609-614. https://doi.org/10.1097/00005537200104000-00010

6. Yenigun A, Gun C, Uysal II, Nayman A. Radiological classification of the infraorbital canal and correlation with variants ofneighboring structures. Eur Arch Otorhinolaryngol 2016;273(1):139-144. https://doi.org/10.1007/s00405-015$\underline{3550-8}$

7. Karki S, Pokharel M, Suwal S, Poudel R. Prevalence of Anatomical Variations of the Sinonasal Region and their Relationship with Chronic Rhinosinusitis. Kathmandu Univ Med J 2016;56(4):342-346. Available from: https://pdfs. semanticscholar.org/a $338 /$ a4ec29bc76d16cde9e735fb295f4c3e779c0.pdf [Accessed 2nd March 2018]

8. Ference EH, Smith SS, Conley $D$ et al. Surgical anatomy and variations of the infraorbital nerve. Laryngoscope 2015;125(6):1296-1300. https://doi.org/10.1002/lary.25089

9. Aggarwal A, Kaur H, Gupta $\mathrm{T}$ et al. Anatomical study of the infraorbital foramen. Clin. Anat 2015;28(6):753-760. https://doi.org/10.1002/ca.22558 
10. Jungell P, Lindqvist C. Paraesthesia of the infraorbital nerve following fracture of the zygomatic complex. Int $J$ Oral Maxillofac Surg 1987;3(6):363-366. https://doi.org/10.1016/S0901$\underline{\text { 5027(87)80160-1 }}$

11. Datta RK, Viswanatha B, Harsha MS. Caldwell Luc Surgery: Revisited. Indian $J$ Otolaryngol Head Neck Surg 2016;68(1):90-93. https://doi.org/10.1007/s12070-0150883-y

12. Chandra RK, Kennedy DW. Surgical implications of an unusual anomaly of the infraorbital nerve. Ear Nose Throat $J \quad$ 2004;83(11):766-767. Available from: https://www.entjournal. com/sites/entjournal.com/files/ archive/www.entjournal.com/Media/ PublicationsArticle/CHANDRA.pdf [Accessed 2nd March 2018] 